\title{
Candelas GaLA
}

Wake Forest University, Winston-Salem, North Carolina, USA

galacs@wfu.edu

ORCID iD: https://orcid.org/0000-0003-0549-0654

Recibido: 12/03/2019 - Aceptado: 24/06/2019

Para citar este artículo / To reference this article / Para citar este artigo

Gala, Candelas. "Contraria sunt complementa o los Orbes del sueño de Clara Janés: una historia

de amor". Humanidades: revista de la Universidad de Montevideo, n 6, (2019): 23-55.

https://doi.org/10.25185/6.2

\section{Contraria sunt complementa o los Orbes del sueño de Clara Janés: una historia de amor}

Resumen: En Orbes del tiempo, Clara Janés ofrece un muestrario de los "orbes" a los que accede el sueño poético, todos ellos asociados de alguna manera con áreas de la física (variables ocultas, indivisibilidad y enredos cuánticos, multiplicidad de universos, relatividad, función de onda, supersimetría, teorías del caos) en cuyas formulaciones la autora identifica paralelos con experiencias a nivel subjetivo e interior. Los poemas articulan encuentros entre polos que tradicionalmente se excluyen mutuamente (sujeto/objeto, cuerpo/mente, interior/exterior) evidenciando el principio de complementariedad de Niels Bohr, por lo que se hace posible elucidar el contenido perceptual del fenómeno. Cuanto más la hablante se inserta en la trama cósmica más se vincula, como en el amor, con la creatividad del cosmos aprehendiendo la vida que allí se sustenta.

Palabras clave: principio de complementariedad, enredos cuánticos, relatividad, teorías del caos, función de onda, variables ocultas. 


\title{
Contraria sunt complementa or Clara Janés's Orbes del sueño: A Love Story
}

\begin{abstract}
In Orbes del sueño, Clara Janés offers a sample of the "orbs" that dreaming makes accessible, all of which are somewhat associated with areas in physics (hidden variables, quantum indivisibility and entanglements, multiple universes, relativity, wave function, supersymmetry, chaos theories...). In these formulations, the author finds parallels with subjective and internal experiences. Poems articulate encounters between poles that are traditionally opposed and mutually exclusive (subject/object, body/mind, inside/outside...) exemplifying Niels Bohr's complementarity princile by which it becomes possible to elucidate the perceptual content of the phenomenon. The more the poetic speaker inserts herself into the cosmic web, the more she experiences a love-like relationship with the creativity of the cosmos and apprehends the life that it sustains.
\end{abstract}

Keywords: principle of complementarity, quantum entanglements, relativity, chaos theories, wave function, hidden variables.

\section{Contraria sunt complementa ou os Orbes del sueño de Clara Janés: uma história de amor}

\begin{abstract}
Resumo: Em Orbes del sueño, Clara Janés oferece uma amostra dos "orbes" aos quais o sonho poético acessa, todos eles associados de alguma forma a áreas da física (variáveis ocultas, indivisibilidade e entrelaçamentos quânticos, multiplicidade de universos, relatividade, função, teoria das ondas, supersimetria, caos) em cujas formulações 0 autor identifica paralelos com experiências em nível subjetivo e interno. Os poemas articulam encontros entre polos tradicionalmente exclusivos (sujeito / objeto, corpo / mente, interior / exterior) evidenciando o princípio de complementaridade de Niels Bohr, para que seja possível elucidar o conteúdo perceptivo do fenômeno. Quanto mais o orador é inserido na trama cósmica, mais ele se liga, como no amor, à criatividade do cosmos que apreende da vida que ali é sustentada.
\end{abstract}

Palavras-chave: princípio de complementaridade, entrelaçamento quântico, relatividade, teoria do caos, modelo de onda, variáveis ocultas. 


\section{La polaridad complementaria. Preliminares}

En Orbes del sueño (2013) de Clara Janés, la elaboración poética se abre a unos ámbitos u orbes inspirada por una gran nevada que lo cubre todo de blanco y que es lo primero que ve la hablante al despertarse ${ }^{1}$. Y en esa blancura empieza a percibir huellas, muchas de ellas dejadas por los pájaros que la hablante interpreta como mensajeros de otros niveles de realidad, transmitiendo indicios reveladores de algún enigma o misterio cósmico ${ }^{2}$. Y así se refleja en las fotografías de la nevada con versos trazados sobre ellas y que se incluyen en el libro junto a los poemas ${ }^{3}$. Sus títulos ofrecen un muestrario de los "orbes" a los que accede el sueño poético, todos ellos asociados de algún modo con áreas de la física, así, la indivisibilidad cuántica, los enredos de la telaraña cósmica, la multiplicidad de universos, la relatividad, la función de onda, la supersimetría, la numerología, las bifurcaciones en la teoría del caos, las variables ocultas... El libro también incluye numerosas citas de filósofos tanto occidentales como del Este, de escritores, pensadores, místicos y, especialmente de teóricos de la física ${ }^{4}$. Dichas citas sirven de epígrafe anunciando los temas que se van a tratar, pero también se insertan en el medio y al final de las secciones ${ }^{5}$. Su función, entonces, es varia pues no solo sirven para anticipar la elaboración del tema en los poemas, sino también

1 En su ensayo "Las ecuaciones de la poesía: para una lectura de Orbes del sueño", Janés habla de cómo empezó a gestarse Orbes a partir de la nevada que cayó una noche, que fue lo primero que vio al despertar, y las fotos que hizo de ella. En Nadia Mékouar-Hertzberg, ed., Secretos y verdades en los textos de Clara Janés / Secrets and Truths in the Texts of Clara Janés (Bern: Peter Lang, 2014), 12.

2 Las huellas de los pájaros le parecieron que expresaban “conceptos científicos”, en Clara Janés, "Las ecuaciones de la poesía: para una lectura de Orbes del sueño", 11.

3 Orbes es un homenaje a Sor Juana con quien Janés comparte la búsqueda "del sentido de cuanto nos rodea y de nosotros mismos". Discrepa de la poeta mexicana en los logros de la búsqueda que para Janés no son de tipo visionario, según escribió Octavio Paz, sino intelectual. Para la hablante poética de Janés la existencia tiene sentido por su interacción con el entorno, y no se trata de trascender a un plano superior sino de percibir la revelación del cosmos en toda su fuerza magnética (ver la conferencia de Janés "Mi homenaje a Sor Juana". Texto enviado por la autora).

4 La presencia de la mística en los escritos de Janés ha sido objeto de estudio de muchos críticos y corroborada por la misma Janés. En el discurso de recepción del Premio Nacional de las Letras Españolas Teresa de Ávila, Janés afirma que la cuestión mística es una presencia en su vida. De Sta. Teresa, Janés admira y comparte las tendencias antagónicas, su "vivo sin vivir en mí", que movieron a la santa entre su deseo de aventuras caballerescas y su intensa vida interior, "Discurso de recepción del Premio Nacional de las Letras españolas Teresa de Àvila", en Anne M. Pasero, ed., Clara Janés. El fuego invisible" (Àvila: Excelentísimo Ayuntamiento de Àvila, 2012), 12-13. La contradicción entre esos deseos, entre una activa vida exterior y otra igualmente activa e intensa en la interioridad es fundamental en la poética de Janés, como se elabora en el presente ensayo.

5 Janés dice que en todo el libro "late el asombro de la confluencia entre los dichos de los antiguos y los más actuales", en "Las ecuaciones de la poesía: para una lectura de Orbes del sueño", 15. 
para corroborar las perspectivas y para servir de conclusión a lo tratado con el soporte de la autoridad del autor o autora citados.

Como anuncia el título de este ensayo, la complementariedad de contrarios, ya sea entre sujeto y objeto, intelecto e imaginación o lo poético-imaginativo con lo analítico-científico, marca el conocimiento del universo al que llega Janés. Sus poemas articulan el encuentro entre el sujeto observador-la poeta en este caso-, y el objeto observado-el cosmos-, y las opciones que proceden de ese encuentro y que determinan el conocimiento y su configuración en el lenguaje o escritura.

Contraria sunt complementa [los contrarios son complementarios] es una expresión inscrita en el escudo de armas del físico Niels Bohr, diseñado en 1947 cuando a Bohr se le concedió la orden danesa del Elefante, honor normalmente reservado a miembros de familias reales y a presidentes de estados extranjeros. Dicho escudo fue colgado al lado del escudo de armas del rey en la iglesia del Castillo Frederiksborg en Hillerod. En él, y además de la inscripción, Bohr eligió el símbolo chino del yin-yang por representar dos elementos de la naturaleza que son opuestos pero inseparables y, en la misma línea, la idea central del instituto que Bohr dirigió fue que no hay progreso sin paradoja ${ }^{6}$.

La paradoja sustenta el principio de la "complementariedad" de Bohr, término que el físico usó por primera vez para definir su teoría física en una conferencia en Como, Italia, en septiembre 1927 . El principio de complementariedad se encuentra en la base de la indagación que Janés lleva a cabo en Orbes, pudiendo extenderse a su obra en general. De entre muchos de los libros de Janés enfocados en la física, he elegido Orbes porque ofrece un tipo de muestrario, casi enciclopédico, de los temas más candentes de la física y su importancia para esta poeta ${ }^{8}$. En esos temas la hablante encuentra formulaciones científicas de situaciones y temas que corren paralelos a los experimentados a nivel subjetivo e interior.

6 John Wheeler, "Physics in Copenhagen in 1934 and 1935", en Niels Bohr. A Centenary Volume, eds. A. P. French y P. J. Kennedy (Cambridge, Mass.: Harvard University Press, 1985), 223-224. Este ensayo es parte de un estudio más amplio sobre las conexiones entre poesía y física en la obra de Clara Janés.

7 R. V. Jones, "Complementarity as a Way of Life", en Niels Bohr. A Centenary Volume, 320.

8 Para un estudio panorámico sobre las conexiones entre la obra de Clara Janés y las ciencias, véase Antonio Ortega, "El arco y la flecha: ciencia y poética en la escritura de Clara Janés", Épistémocritique 16 (octubre 30, 2017). http://epistemocritique.org/category/la-revue/volume-16-vers-une-epistemocritique-hispanique/. Ortega trata muchos de los puntos elaborados en el presente ensayo a lo largo de la obra de Janés. 
El principio de la complementariedad de Niels Bohr describe una situación donde es posible considerar un evento o fenómeno mediante dos modos distintos de interpretación. Aunque esos modos se excluyen mutuamente, también se complementan y es mediante su yuxtaposición como se hace posible elucidar el contenido perceptual del fenómeno?. Wolfgang Pauli propuso la posibilidad de considerar los instrumentos de medición como extensiones del observador y sus órganos sensoriales-que en poesía se corresponderían con el lenguaje-, y vio que la conciencia es donde tiene lugar la síntesis del pensamiento analítico / racional y místico / irracional ${ }^{10}$. Así parece entenderlo Janés pues en La palabra y el secreto reconoce que el intercambio continuo entre entorno, cuerpo y mente constituye una rueda o red donde todo se relaciona ${ }^{11}$. A su vez, Biruté Ciplijauskaité menciona la presencia en Janés de "los tres cuerpos, el del escritor, el de lo otro y el de la escritura" como espacios de energía y determinantes del movimiento del texto ${ }^{12}$.

La inclusión de imágenes y citas múltiples procedentes de distintos autores, civilizaciones y épocas no es nueva en Orbes. Janés recurre a ella en la mayoría de sus obras, reflejando su confesada entrega a la transdisciplinariedad ${ }^{13}$. Según

9 Werner Heisenberg, "Reminiscences from 1926 and 1927”, en Niels Bohr. A Centenary Volume, 170. R. V. Jones, "Complementarity as a Way of Life", en Niels Bohr. A Centenary Volume, se refiere al "Golden Mean" [promedio, término medio] de Aristóteles y a Hegel quien dijo que "Every truth, every reality, is the unification of two contradictory elements or partial aspects which are not merely contrary like black and white but contradictory, like same and different" [Cada verdad, cada realidad, es la unificación de dos elementos o aspectos parciales contradictorios que no son meramente contrarios como blanco y negro sino contradictorios, como igual y diferente]. (Todas las traducciones son mías). Como ejemplo Hegel se refirió a la cantidad y la cualidad, tan diferentes en apariencia, pero muy relacionadas ya que un cambio en cantidad puede producir un cambio en cualidad, 321. Con relación al principio de complementariedad, Wheeler cita uno de los dichos favoritos de Bohr, que una gran verdad es una verdad cuyo contrario u opuesto es también una gran verdad, John A. Wheeler, "Physics in Copenhagen in 1934 and 1935", en Niels Bohr. A Centenary Volume, 223. En "Poética de la rebelde ebriedad", en Clara Janés. El fuego invisible, 73, Janés habla de la analogía en términos que se aplican a la complementariedad. En la frase "lo que está abajo es como lo que está arriba, lo que está arriba es como lo que está abajo" (de la Tabula smaragdina), la analogía "procura un tipo de conocimiento enigmático" semejante, según Janés, al que hizo decir a San Pablo "per visibilia ad invisibilia”. Gracias al ritmo que introduce la analogía, el poeta salta del tiempo a otro nivel situándose en la unidad primordial, entregándose "a la intuición de la unidad en la diversidad". El objeto de la poesía es el mundo de lo desconocido pues es el único que puede llevar a otra visión de lo real.

10 Wolfgang Pauli, Writings on Physics and Philosophy, eds. Charles P. Enz y Karl von Meyenn, trad. Robert Schlapp (Berlin: Springer-Verlag, 1994), 153.

11 Clara Janés, La palabra y el secreto (Madrid: Huerga y Fierro, 1999), 12.

12 Biruté Ciplijauskaité, "Magia y misterio en Clara Janés", en Clara Janés. El fuego invisible, 113.

13 Según Ciplijauskaité, Janés es posiblemente la poeta con el más amplio trasfondo: filosofía, mística oriental, mitología, teoría literaria, lecturas de otros países y, aunque Ciplijauskaité no lo menciona, de la física. Ha cultivado todos los géneros: poesía, novela, ensayo, relato, crítica literaria, teatro y es ganadora del Premio Nacional de Traducción, trabajando con el turco, persa, checo, rumano, inglés, francés, portugués, italiano, alemán, catalán, Biruté Ciplijauskaité, "Magia y misterio en Clara Janés”, en Clara Janés. El fuego invisible, 110. 
Basarab Nicolescu, autor del Manifiesto de la transdisciplinariedad y cuyos teoremas poéticos Janés ha traducido, la transdisciplinariedad "es una tentativa de hallar un equilibrio entre el saber y el ser", de conciliar epistemología y ontología, lo cual es un objetivo también en Orbes y en la obra de Janés, en general. Su novedad se origina, según Nicolescu, en la "cosmodernidad científica" donde coincide de nuevo con Janés y su acercamiento transdisciplinario a cuestiones cosmológicas ${ }^{14}$. Los "teoremas poéticos" de Nicolescu representan un encuentro entre la física cuántica, la filosofía de la naturaleza y la experiencia interior, las áreas que también se dan cita en la obra de Janés.

En la importancia que tanto Bohr como Pauli dan al observador, ambos físicos reconocen la indeterminación que también caracteriza los instrumentos de observación que, en la escritura corresponden a la poeta con su lenguaje y al sistema observado o el cosmos, indeterminación debida a que cada observación tiene un carácter único lo cual dificulta tener una certeza clara del grado de influencia del sujeto observador en lo observado. Por eso hay que admitir, como ya ha hecho la ciencia física desde 1927 y los desarrollos de la mecánica cuántica, que no es posible comprender la totalidad del universo. Se concluye entonces, como hace Pauli, que esta indeterminación da entrada a un elemento irracional en la física ${ }^{15}$.

En el acercamiento poético de Janés la indeterminación es, si cabe, aún más incierta. Como el observador en la física cuántica, la poeta en Janés está inserta en la totalidad del fenómeno del universo, ya que se trata de la trama cósmica o "entanglements" [enredos], el término usado por Bohr para connotar la indivisibilidad de los elementos del universo ${ }^{16}$. Los "enredos" o "intra-actuación” de los elementos en la trama cósmica suponen una total

14 Basarab Nicolescu, Teoremas poéticos. Fotografías de Karl Blossfeldt. Selección y traducción de Clara Janés (Madrid: salto de página, 2013), 30 y Manifesto of Transdisciplinarity, tr. Karen-Claire Voss (Albany: State University of New York Press, 2002), 37-38. Para un detallado análisis de la transdisciplinariedad, véase principalmente el ensayo de Jorge Sarquís y Jacob Buganza, "La teoría del conocimiento transdisciplinar a partir del Manifiesto de Basarab Nicolescu", Fundamentos en Humanidades 10.1 (19, 2009): 43-55.

15 Wolfgang Pauli, Writings on Physics and Philosophy, 39, 36, 40.

16 Como explica Karen Barad, Bohr se sirve del término "fenómeno" para significar la totalidad que supone la interacción entre los "objetos de la investigación" y "las agencias o agentes de la observación", entendiendo el fenómeno como los enredos cósmicos o "entanglements", Karen Barad, Meeting the Universe Halfway. Quantum Physics and the Entanglement of Matter and Meaning (Durham y London: Duke University Press, 2007), 427, notas 47 y 48. Fue Schrödinger quien introdujo el término “entanglement” [enredo] en 1936 en un ensayo motivado por el artículo que escribieron Einstein, Podolsky y Rosen. 
revisión de la causalidad y de la creencia de que la naturaleza posee una esencia fija y estática pues se trata de un devenir en constante intra-actividad ${ }^{17}$.

Hay que hablar, entonces, de una totalidad cuántica [“quantum wholeness"] o inseparabilidad entre sujeto y objeto, lo consciente y lo inconsciente ${ }^{18}$. La insistencia en el fenómeno como totalidad data en Bohr desde 1937, entendiendo por tal que cada fenómeno atómico es una unidad irreducible epistemológicamente ${ }^{19}$. En Janés se traduce en la inserción de la poeta en y con el entorno que observa y del que es parte, a diferencia del observador distanciado en la física clásica. David Bohm explica esa totalidad con el ejemplo de un "pattern" o "patrón” en una alfombra donde flores y demás rasgos "are disjoint objects of interaction" [objetos desarticulados de interacción $]^{20}$. Igualmente, en una situación cuántica, el objeto observado, el instrumento de observación, las condiciones para el experimento y los resultados del experimento son aspectos de un único "pattern" que se destacan gracias al modo de articularlos en el discurso o lenguaje. Como no estamos ni distanciados del mundo ni somos superiores a él, sino parte de su constante reconfiguración, el conocimiento resulta ser una práctica de enredo o involucración física ${ }^{21}$. En la formulación de Janés se trata de una "ignota trama" en la "curvatura del espacio" donde se da la inseparabilidad del todo, y el aire es el mediador que "transmite y encadena"22. En la gestación de Orbes, Janés menciona las muchas lecturas que llevó a cabo pues el proyecto era el "de acercarse a una teoría del conocimiento" "23. Como indica el mismo título del libro, el acercamiento no se ciñe al universo y al intelecto, sino que incluye el aspecto interior onírico o de la imaginación. El texto, por tanto, ofrece una fusión de realidad y ensoñación, o de elaboración poético-física de cuestiones científicas. Y cuanto más se profundiza en la búsqueda, en la relación que la poeta / observadora entabla con el universo, más se confirma la impresión de que se trata de una historia de amor en la que, inserta en la trama cósmica y sus enredos, la hablante participa de la creatividad del cosmos

17 Barad es quien acuña el término de "intra-actividad" para describir el constante "devenir" [becoming] del universo, diferenciándolo de “interacción”. Ese devenir desbanca la metafísica del individualismo y su creencia de que hay objetos discretos con características inherentes, Karen Barad, Meeting the Universe Halfway. Quantum Physics and the Entanglement of Matter and Meaning, 33, 422, nota 15, 424-425, nota 30.

18 Karen Barad, Meeting the Universe Halfway. Quantum Physics and the Entanglement of Matter and Meaning, 196.

19 Edward MacKinnon, "Bohr on the Foundations of Quantum Theory", en Niels Bohr. A Centenary Volume, 119.

20 David Bohm, “On Bohr's Views Concerning the Quantum Theory”, en Niels Bohr. A Centenary Volume, 157.

21 Karen Barad, Meeting the Universe Halfway. Quantum Physics and the Entanglement of Matter and Meaning, $341,342$.

22 Clara Janés, Orbes del sueño (Madrid: Vaso roto, 2013), 31, 32.

23 Clara Janés, Orbes del sueño, 13. 
aprehendiendo la vida que allí se sustenta ${ }^{24}$. Y así lo confirma la autora misma: "Sentir un vínculo ... como algo que logra destruir el tiempo y el límite ... qué semejante al amor" ${ }^{25}$. Y es así porque los poemas se enuncian a partir del "yo" de la hablante, quien se corresponde en términos de la física con el aparato o instrumento de medición / observación, el entorno al que se dirige su observación y la escritura donde configurar esa observación. La relación de la hablante como instrumento de medición u observación no se sitúa a distancia del entorno sino en una relación de proximidad como "reconocimiento total del ser del otro"26.

En Jardín y laberinto, relato autobiográfico sobre su infancia en el jardín de Pedralbes, entregada a ensoñaciones sobre el cielo nocturno y aprensiva del mundo exterior, Janés confiesa cómo se iba dando cuenta de que "lo imaginario puede hallarse fuera de uno, tomar cuerpo y estar vivo"27. Más tarde, reflexionando sobre esa fascinación infantil con el cielo nocturno, entendería que quizá se debió a percibir la "armonía celeste” y el "equilibrio matemático" a lo que se uniría "la fuerza magnética del negro, acaso la energía oscura, y con la gravedad" 28 . La creciente influencia del exterior u otredad la indica Janés en la "Poética de la rebelde ebriedad" donde, citando a Hermann Broch en un texto sobre "La carta de Lord Chandos" de Hofmannsthal, destaca que "la tarea del artista consiste precisamente en esta total identificación con su objeto" 29 . La observadora en Janés recrea la situación cuántica de enredo o abrazo curvo con el objeto observado en un fenómeno de totalidad, indivisibilidad e intra-actuación. En esa

\footnotetext{
24 Ciplijauskaité indica que el amor como deseo equivale a vida en la obra de Janés, Biruté Ciplijauskaité, "Magia y misterio en Clara Janés", en Clara Janés. El fuego invisible, 111. Y según Mariarosa Vidoni Scaramuza, Janés se inspira en recientes hipótesis científicas sobre vibraciones de la materia como fuente del universo, llegando a un tipo de "misticismo cósmico" unido al tema del amor visto como motor del universo y de la poesía, "Poesía y misterio en Clara Janés", en Clara Janés. El fuego invisible, 165. La búsqueda del conocimiento en Janés se enlaza con su teoría del amor, algo que, según Jaime Siles, le viene de Cirlot, "Clara Janés: Vida secreta de y en las palabras", en Movimientos insomnes. Antología poética (1964-2014) de Clara Janés, ed. Jaime Siles (Barcelona: Galaxia Gutenberg, 2015), 18.

25 Clara Janés, Jardín y laberinto (Madrid: Debate, 1990), 112.

26 Clara Janés, Jardín y laberinto, 118. Luis Antonio de Villena reconoce en Janés “una inquebrantable vocación lírica y buscadora", "Esencias materiales (sobre el libro Fractales)", en Clara Janés. El fuego invisible, 130. Y Janés confirma esa plena fusión con el cosmos cuando en La palabra y el secreto, 11, indica que la célula está "en intercambio continuo con el entorno", intercambio que es movimiento y vida.

27 Clara Janés, Jardín y laberinto, 77.

28 Clara Janés, "Las ecuaciones de la poesía: para una lectura de Orbes del sueño", 10.

29 Clara Janés, "Poética de la rebelde ebriedad", 72.
} 
intra-actuación el amor es el impulso que lleva a la creatividad y a afirmar la $\operatorname{vida}^{30}$.

Janés no menciona explícitamente en este libro el principio de complementariedad desarrollado por Bohr, pero su base filosófica es evidente en todas sus elaboraciones sobre la realidad. Se manifiesta en su relato autobiográfico, Jardín y laberinto, donde el jardín, como lugar privado y recogido incluye la expansión en la inmensidad cósmica de la niña Clara observando el cielo nocturno -la niña que fue Janés en el jardín de su casa en Pedralbes-. La noche para ella representaba y representa "el sueño del universo". El hurgar en la propia interioridad, en la "vida subterránea" se fundía con el vuelo imaginativo sobre el misterio que presentía en la oscuridad de la noche ${ }^{31}$. Junto a la riqueza de esta vida interior y privada, la niña experimentaba un "laberinto" en su propia mente al tratar de comprender lo que sucedía en el exterior y, también, en el cúmulo de información que sospechaba en los muchos libros en la biblioteca de su casa. De entre ellos Janés recuerda los del colegio, especialmente el de ciencias naturales que aún conserva pues, como ella misma explica, es el que más le unía a su vida vinculada en el jardín de la infancia. Y, tras haber oído al físico Ilya Prigogine, confiesa haber empezado a acumular libros sobre temas científicos de Schrödinger, Fitjof Kapra, Sherrington, Hawking, George Smooth, Gell-Mann y Prigogine ${ }^{32}$.

\section{La complementariedad en Orbes del sueño}

La polaridad complementaria entre el interior y el exterior se articula en el texto titulado "Leyenda" con que se abre Orbes, así como en las muchas citas en este libro y a lo largo de su obra. Ya se apuntó el comentario de Janés en su "Discurso" de aceptación del Premio Teresa de Ávila sobre la disyuntiva de la santa entre sus deseos de efectuar aventuras caballerescas y su rica vida interior. Y, al citar en el mismo discurso a Ibn Arabí, el místico murciano del siglo XII, elige una declaración de complementariedad de contrarios: "No se

30 Karen Barad, Meeting the Universe Halfway. Quantum Physics and the Entanglement of Matter and Meaning, 422, nota 15.

31 Clara Janés, Jardín y laberinto, 8, 11. Para Anne M. Pasero, la escritura de Janés es un proceso de indagar debajo de la superficie, espejo de la subconsciencia, de su "vida subterránea", "hundiéndose en el no saber" que se ilumina mediante un enfoque subjetivo, "La autobiografía como expresión singular posmoderna: Jardín y laberinto", en Clara Janés. El fuego invisible), 120.

32 Clara Janés, "Discurso de recepción del Premio Nacional de las Letras Españolas Teresa de Ávila”, 22-23, 30. 
conoce el mundo sino en la medida en que se conocen las sombras"33. Y en un volumen en honor a Janés, el poeta portugués Antonio Ramos Rosa dedica un poema a la autora donde reconoce la importancia de los complementarios en su obra: "Si tú cantas es porque quieres nacer partiendo del fondo / Y vibrar porque sientes que la plenitud y la vacuidad / Constituyen la unidad transitiva del ser" ${ }^{34}$.

La opción de una leyenda para abrir Orbes insiste en las dualidades, pues una leyenda es una narración donde hechos naturales se mezclan con otros sobrenaturales, la ficción con la verdad, el mito con la realidad. La "Leyenda" en Orbes es un relato en prosa donde se cuenta la aventura en pos del conocimiento que luego se elaborará en cada una de las nueve secciones del libro. Supone una aportación poético-imaginativa a temas centrales en la ciencia física, situando la indagación en un plano donde física y elaboración poética, intelecto y sueño son contrarios que se complementan. Esos complementarios de ciencia y poesía, centrales en Janés, se elaboran en el ensayo de la misma autora sobre este libro, "Las ecuaciones de la poesía: para una lectura de Orbes del sueño". Allí Janés intuye que "un poema se desarrolla como una ecuación y lleva a un resultado", que "hay poesía en las ecuaciones y ecuaciones en la poesía" y que "la conciencia de que la poesía se escribe como una ecuación, es algo muy antiguo" en ella. Ecuaciones y poesía conducen a una revelación, aunque siempre quede un resto de misterio e incertidumbre. Y si a la poesía le interesa tratar temas como el paso del tiempo, la levedad de la vida, el amor, los límites, la ciencia trata de la relatividad, la incompletitud y la incertidumbre ${ }^{35}$.

Tal y como nos cuenta en la "Leyenda", la nieve que ve al despertar se le aparece como un posible regalo de la noche que, aunque encubre el secreto de la oscuridad y el enigma del cielo nocturno, contiene un gran potencial de significación ${ }^{36}$. Se da cuenta de que para poder empezar a descifrar ese potencial hay que recurrir al sueño y a la música pues el intelecto no basta. De esa manera puede percibir las ondas y vibraciones del universo donde lo microscópico de las micropartículas y los microtonos de la música cósmica se funden con lo macroscópico de los astros.

33 Clara Janés, "Discurso de recepción del Premio Nacional de las Letras Españolas Teresa de Ávila", 16.

34 Anne M. Pasero, ed., Clara Janés. El fuego invisible, 30.

35 Clara Janés, "Las ecuaciones de la poesía: para una lectura de Orbes del sueño", 4, 9, 11, 4, 8. Para Jaime Siles, Orbes del sueño es un libro de ciencia que intenta "poetizar la armonía cósmica de las constelaciones y galaxias, las partículas y los pensamientos", en "Clara Janés: Vida secreta de y en las palabras", 38.

36 Clara Janés, "Las ecuaciones de la poesía: para una lectura de Orbes del sueño", 12. 
Inserta en las fluctuaciones del cosmos, la hablante pronto constata el efecto que estas tienen en su expansión — de igual modo que la ensoñación poética le lleva a experimentar la realidad a distintos niveles-. Llamado redshift [desplazamiento hacia el rojo], el fenómeno de la expansión del universo amenaza con romper los lazos que constituyen la trama cósmica dando lugar a los agujeros negros. Ante efectos tan funestos la hablante se pregunta, ¿cuál debe ser el papel del observador respecto al cosmos, objeto de su observación? Y ¿cuál es la función del cerebro, del pensamiento, del deseo? La actividad del cerebro es el deseo, como afirma más adelante, y se mueve con el pensamiento pues lo que captan los sentidos, la cabeza lo concreta ${ }^{37}$. La hablante va constatando que la presencia del sujeto en la observación es fundamental, y comprende que la mente también es un astro con sus satélites y el mundo interior y exterior son parte del mismo universo.

La poeta baraja términos como razón, conciencia, memoria, inteligencia..., evaluando su significado en la indagación del entorno, y observa que hay una memoria del cuerpo, del mismo modo que la inteligencia se funde con el azar, con la materia, investigando sobre las causas, los efectos, sobre la interrelación de efecto y causa y de causa y efecto y, en sí, sobre la vida. El conocimiento es corporal tanto como intelectual, corroborando lo que ya dijo Ramón Gómez de la Serna de que la escritura es "un estado de cuerpo" pues, abiertos todos los poros de la sensibilidad, el cuerpo recoge los indicios del exterior $^{38}$. La realidad se constituye en base a complementarios implicados en una telaraña de enredos cuánticos. Empeñarse en idealizaciones de estatismo supondría una entropía positiva donde el final es la muerte por calor. Hay que adentrarse en los enredos de esa danza, los que Bohr identificó como esenciales en la trama del universo. Y para ello, un acercamiento reducido a la razón no es suficiente pues no se trata de movimientos lineales sino de una circularidad donde la certidumbre ha sido sustituida por las probabilidades e incompletitud de la realidad cuántica.

Janés llega a la certeza de que almacenamos todo lo que percibimos desde el nacimiento y de que existe en nosotros un conocimiento anterior, pues el gen es portador de memoria. Lo que se requiere es una cierta sensibilidad para captar en el presente ideas que pertenecen a pasados remotos ${ }^{39}$. Se plantea así la misma situación que en la mecánica cuántica en la que el observador 
deja de ser un espectador pasivo para pasar a ser un agente activo ${ }^{40}$. Y como Janés constata y se plantea en el principio de incertidumbre de Heisenberg, la complementariedad entre sujeto y objeto introduce la probabilidad en física. La entrada de elementos personales y subjetivos en la observación del cosmos lleva a la hablante a constatar la incompletitud del conocimiento. La creencia en que somos poseedores de un conocimiento total sobre un universo estático y fijo que controlamos por la razón, como presupone la física clásica, es insostenible pues carecemos de la llave que revele en su totalidad el enigma del universo. Inmersos como estamos en el universo que observamos, pues, como afirmó Bohr, somos parte de él, no es posible mantener la idealización de la física clásica de un conocimiento objetivo a distancia.

La misma situación viene a darse en la creación poética donde la hablante configura el universo que observa y en el que está inserta según unas opciones formales que a su vez generan múltiples connotaciones y significados. Al igual que la introducción de algún elemento en la conciencia provoca alteraciones en el inconsciente, la introducción de elementos en el observador altera el objeto observado. El grado de objetividad en esta situación se cifra en el concepto matemático de la probabilidad que, en términos poéticos, gira en torno a las acepciones y connotaciones varias que el texto sugiere ${ }^{41}$.

Otro aspecto que relaciona a Bohr con Janés es la preocupación que ambos tienen por el lenguaje ${ }^{42}$. Para Bohr las cuestiones filosóficas no tenían que ver con la existencia o la realidad o con las limitaciones de la razón humana, como explica Petersen, sino con la comunicación ${ }^{43}$. Y algo semejante se aplica a Janés para quien las ecuaciones, teoremas y principios científicos tienen valor en cuanto pueden ser articulados de forma poética revelando su participación en lo irracional.

En la inseparabilidad de los elementos cósmicos, la "relatividad" es un elemento fundamental debido a que la proximidad en los enredos cuánticos condiciona el conocimiento. Y, como explora la hablante en las distintas secciones del libro, la relatividad del conocimiento cuántico conduce a concebir no un universo único, sino una multiplicidad donde el centro es igualmente múltiple. Un refugio sería recurrir a los números como medio de lograr más transparencia, con el cero como potencial de estabilidad, aunque pronto se constata que su mantenimiento conduciría a un absolutismo

40 Wolfgang Pauli, Writings on Physics and Philosophy, 152.

41 Wolfgang Pauli, Writings on Physics and Philosophy, 43.

42 John A. Wheeler, "Physics in Copenhagen in 1934 and 1935", en Niels Bohr. A Centenary Volume, 392.

43 Aage Petersen, "The Philosophy of Niels Bohr", en Niels Bohr. A Centenary Volume, 301. 
contrario al movimiento de la vida. La indagación que se lleva a cabo en Orbes lleva a admitir el hecho de que para acceder a la realidad el conocimiento tradicional debe ser suplantado por otro nuevo cuya base y fundamento es la complementariedad de elementos contrarios.

\section{$* * *$}

La cita de Einstein que precede a toda la colección de Orbes expresa el rechazo del físico del universo desordenado que se abrió con la física cuántica: "No puedo soportar la idea de un universo desordenado" " Einstein nunca comulgó con la idea de que no fuera posible llegar a un conocimiento claro y ordenado del universo, según señalaba el principio de incertidumbre de Heisenberg. Y parece ser que, como indica la misma Janés, fue su hija Adriana quien de adolescente le "regaló" esa frase de Einstein a su madre. ¿Compartía Adriana la opinión de Einstein y/o la preocupación del físico y de su madre por el universo y sus leyes? Como curiosa y posible contrapartida a esta cita inicial, el libro se cierra con una sección que, titulada "Bifurcaciones sucesivas", se refiere a la teoría del caos de Ilya Prigogine donde las bifurcaciones dan pie a otro orden que permite que el sistema físico se autoorganice. Por tanto, el libro marca un proceso desde los postulados y expectativas de Einstein, encapsulados en la física tradicional, a los de la física cuántica. En la evidente disparidad entre el mundo ordenado de la física clásica y el "desordenado" e incierto de la física cuántica se enfocan las investigaciones de este libro. El texto en prosa de la "Leyenda", que vengo de analizar, trata los temas desarrollados poéticamente en cada una de las nueve secciones del libro.

Es comprensible que la primera sección, "Blanco inicial", sea el punto de partida para inscribir esta historia de amor que es la indagación de Janés. Y la indagación en esta sección va enmarcada por Heráclito que exhorta a "conocer la inteligencia que guía todas las cosas a través de todas" destaca de esta cita es la totalidad que debe marcar el conocimiento al que nos exhorta Heráclito, pues como búsqueda de amor, conlleva la proximidad con el objeto y entorno de la búsqueda. Implica, así, un acercamiento que es tanto epistemológico como ontológico, pues no se trata de conocer observando a distancia y desde fuera el mundo, sino metiéndose en y "a través" del mundo y de sus cosas. Concierne a una inteligencia penetradora que "transverbera" y que, como tal, proyecta en la investigación física el mismo tipo de "trance" 
que el místico experimenta al participar del conocimiento divino. Y la referencia a la mística no es fortuita. El papel que juega la mística en Janés es fundamental, aunque no cabe en este ensayo llevar a cabo un análisis a fondo que, además, ya ha sido tratado por un gran número de estudiosos y confirmado por la autora misma. Pero como se señalará más adelante, esta aventura de conocimiento conducirá a un nuevo tipo de "diálogo" con la naturaleza (en términos de Prigogine) donde las revelaciones de la física cuántica se funden con la mística, la alquimia, las filosofías orientales y la poesía, llegando a una nueva concepción del conocimiento.

La ausencia de puntuación pide leer los poemas en su continuidad, lo cual transmite al texto esa "transverberación” de que habla Heráclito y que Barad traduce como la inter-actividad de todos los elementos del universo en su constante devenir.

Tras la cita de Einstein, la sección "Blanco inicial" consiste en cuatro poemas donde se perfila el comienzo de esta historia de amor que es la indagación del universo a través de la ensoñación poético-imaginativa. La blancura de la nieve, o de la página en blanco, evoca un silencio como armonía interior donde ya se empiezan a notar resonancias y movimientos que se asocian con la música, la de Arvo Pärt, en particular, facilitando un inicio para la búsqueda del que ya no hay posibilidad de regreso hacia el origen porque la flecha del tiempo marca la irreversibilidad cuántica ${ }^{46}$. Paradójicamente a la blancura de la nieve / página, a este nivel lo que domina es la negrura (nigredo en la tradición de la alquimia) del desconocimiento, aunque ya en esa negrura parecen percibirse las "solitarias" que cantan. Es posible que esas "solitarias" se refieran a las "variables ocultas" que ofrecen indicios para desenvolverse en esta oscuridad inicial ${ }^{47}$. La alusión a estas variables ocultas se puede explicar como seguimiento a la llamada de Heráclito a "meterse en las cosas" y lograr un conocimiento profundo; se explica, también, como una idealización que permitiría resolver las polaridades.

Las “variables ocultas", que Janés trata más elaboradamente en un libro así titulado, son formulaciones alternativas que pretenden restablecer el determinismo de la física clásica que eliminó la escuela de Copenhague y su mecánica cuántica. David Bohm las considera una propuesta de carácter retrógrado pues permitirían introducir un determinismo mecánico propio de

46 Clara Janés, Orbes del sueño, 17, 18.

47 Como en la tradición de la alquimia y de la mística, Janés reconoce en el negro una energía genésica de la que surge el poema como transparencia del saber secreto en que la poeta indaga, Clara Janés, La palabra y el secreto, 92. 
la dinámica clásica, lo cual iba en contra de la propuesta de Bohr de acercarse a los fenómenos como una totalidad dinámica. En este sentido, había que aceptar el indeterminismo como un tipo de desorden irreducible de la naturaleza cuya base era la "indivisibilidad" del cuanta. Esto supone que no es posible analizar la observación en partes, como proponía la física clásica, pues las leyes de probabilidad en la cuántica lo impiden. Por tanto, según Bohr, no se puede hablar de "disturbios" del sistema debido a la observación ${ }^{48}$.

Aun así, Bohm cree que la noción de variables ocultas puede conducir a una nueva manera de pensar sobre las leyes físicas, distanciándonos de las nociones de la física clásica, y a conocer mejor la actividad y el movimiento de la naturaleza que es en sí lo que constituye la física. La existencia de variables ocultas permitiría un tipo de descripción donde es posible y natural decir que las transiciones cuánticas tienen un carácter repentino e impulsivo. Se asume que cuando termina la operación impulsiva o "proceso de medición", las variables ocultas permanecen constantes ${ }^{49}$.

La mecánica cuántica implica un indeterminismo que es reflejo del verdadero comportamiento de la materia. Por tanto, en las medidas hay que considerar la existencia de entidades a un nivel sub cuántico-mecánico que obedecen nuevos tipos de leyes individuales. Esas leyes y entidades constituirían un aspecto de la naturaleza que permanece "oculto". Sin embargo, aunque admitiéramos la existencia de esas variables ocultas, debido al principio de incertidumbre de Heisenberg no podríamos medirlas todas simultáneamente pues la interacción entre el aparato observador y lo observado siempre implica un intercambio de una o más cuantas fluctuando incontrolablemente. Bohm cree en la existencia de ese nivel donde se producen fenómenos nuevos no tratados muy bien en las teorías presentes. Como no podemos creer que hemos llegado a un conocimiento total, lo que propone es la necesidad de probar diferentes vías de investigación ${ }^{50}$.

En los textos de Orbes, la hablante se encuentra en un "vacío invisible" donde la luz es "corteza opaca" 51 . Janés ha asociado el vacío con el silencio y, como en el silencio, percibe en el vacío un pleno de vibraciones que, según señala Basarab Nicolescu, van cargadas de información ${ }^{52}$. Schmelzer puntualiza

\footnotetext{
48 David Bohm, Wholeness and the Implicate Order (London: Routledge y Keagan Paul, 1981), 73, 75.

David Bohm, Wholeness and the Implicate Order, 97, 107, 110.

David Bohm, Wholeness and the Implicate Order, 69, 67, 68, 69, 109, 110.

Clara Janés, Orbes del sueño, 69.

Clara Janés, "Poética de la ebriedad", 69. 
que esas vibraciones tienen una connotación fuertemente creadora ${ }^{53}$. Así las solitarias variables ocultas cantan en la negrura, sugiriendo un nuevo plano de indagación y conocimiento y señalando el germen de la creatividad y de la vida en la música y, por añadidura, en áreas de la imaginación, la fantasía y lo irracional. En "Nota" al final del libro, Janés explica que Orbes es "una forma de agradecimiento a Arvo Pärt, cuya música ha sido mi guía en este trayecto" 54 .

Además de las variables ocultas, como una nueva vía de conocimiento por la que la hablante intenta escapar del indeterminismo cuántico, el libro de Janés propone el sueño como medio de penetrar en esa negrura y vacío. El sueño nos abriría los ojos para "oír" la escala de luz, es decir, para poder apreciar sinestesias que un acercamiento intelectual descartaría ${ }^{55}$. Y lo que se percibe por el sueño es una escala de paralelas que se juntan, lo que contradice creencias establecidas. Los versos aluden a la geometría proyectiva que parte de los principios de que dos puntos definen una recta y de que todo par de rectas se cortan en un punto (cuando dos rectas son paralelas se dice que se cortan en un punto del infinito conocido como punto impropio). Estos fenómenos se producen a distancias enormes por donde transitan los números transfinitos.

En ese avance donde dominan las sinestesias y enredos cuánticos, el entendimiento tradicional de espacio y tiempo se supera en un "más aquíallá" donde los contrarios se dan cita. El cruce de los contrarios se facilita por la existencia de fluctuaciones que aseguran el movimiento del cosmos y la posibilidad de ver "el punto evanescente / que configura / vida". Y es así porque la indagación en el enigma del universo es, en última instancia, la del sentido de la vida. Y la vida se vislumbra en los enredos y fluctuaciones como un punto imposible de fijar ya que su rasgo esencial, la evanescencia,

53 Felix K. E. Schmelzer, "Vibra el vacío’: interpretación de un poema de Clara Janés, a partir de la física cuántica”, en Wort und Zahl. Palabra y número, 219-230 (Heidelberg: Universitätsverlag, 2015), 220.

54 Clara Janés, Orbes del sueño, 18, 95. Más adelante en Orbes Janés cita a Macrobio (33) donde la tradicional separación de alma y cuerpo se disuelve por la música pues su recuerdo se mantiene en el alma mientras está en el cuerpo. En la presentación del libro de Janés, Los números ocultos, Antonio Gamoneda indica cómo la música se desprende de la naturaleza, pues la naturaleza está poseída por la música desde simas hasta clarines. Y afirma que la naturaleza está ordenada por un misterio numérico, Antonio Gamoneda, "Presentación de Los números ocultos", en Clara Janés, Los números ocultos (Madrid: Siruela, 2006), 154, 155.

55 Clara Janés, Orbes del sueño, 20. 
es parte del movimiento cósmico por el que todos los elementos se hallan en lo que Janés denomina la "fuga" 56 .

En los "Fuegos caóticos", segunda sección del libro, hay indicios de que, después de los intentos de superar la incertidumbre cuántica o "fuga", mediante las variables ocultas y el sueño, se entra en el proceso de la creatividad. Mientras que en la interioridad de la hablante hay "meteoros en fuga" como iluminaciones efímeras y "meteóricas' del enigma que, aun así, son reflejos de las estrellas y del misterio cósmico ${ }^{57}$. Al tratarse de "fuegos cáoticos", se introduce el caos y el azar que el libro trata de manera más elaborada hacia el final. En este punto lo caótico de esos fuegos de iluminación efímera apunta a un tipo de creatividad que rompe con la uniformidad de la física clásica. Mientras, en el exterior continúa la nieve fría, pero con deseos de arder y de consumirse.

La cita que precede y abarca esta sección es de Parménides, el presocrático que habla de un ente continuo o totalidad donde luz y noche se dan cita ${ }^{58}$. Esta noción de totalidad es la que muchos siglos después los cuánticos describirían como la indivisibilidad de la naturaleza, los enredos y la telaraña cósmica atravesada por ondas y vibraciones donde espacios y tiempos se $\operatorname{cruzan}^{59}$. Las fluctuaciones en la trama cósmica funden en el presente y el ahora olvido y memoria, presencia y ausencia. En esa fusión de contrarios, la oscuridad es la que da acceso a la luz, y la luz, a su vez, no es luz ni visión ya que exige un descenso hacia la sima donde fluye la nada. Por eso la hablante recurre de nuevo a la música de Pärt donde encuentra, como indicios en la oscuridad, los números y las geometrías moviéndose en un tipo de "danza inmóvil" ${ }^{60}$. En una situación de orden tan lejano de las convenciones, la hablante recurre a una cita del "Gran Upanishad del Bosque" como guía que le oriente. Esa sabiduría le revela que los dioses a seguir son la materia, el aire y la energía vital, siendo esta última el único dios ${ }^{61}$.

\footnotetext{
56 La fuga supone la ausencia de conclusión en la vida y la sucesión y fugacidad en el presente, Clara Janés, $L a$ blanca forma de la fuga (Valladolid: Diputación de Valladolid, 2015), 31. En un poema de ese libro se lee que "la blanca forma / de la fuga / hacia la inapelable incertidumbre / y dar el salto / sobre su íntimo confín / aunque nada se alcance / y la curva se pierda / en el baile de / las variables / ocultas" (33). La fuga conduce a la incertidumbre donde la curva del espacio tiempo se disuelve en la danza de las variables ocultas.

57 Clara Janés, Orbes del sueño, 21.

58 Clara Janés, Orbes del sueño, 23.

59 Sobre la telaraña cósmica o “cosmic web”, véase N. Katherine Hayles, The Cosmic Web. Scientific Field Models \& Literary Strategies in the 20 $0^{\text {th }}$ Century (Ithaca y Londres: Cornell University Press, 1984).

60 Clara Janés, Orbes del sueño, 24, 25, 26.

61 Como explica la misma Janés, "La vida, los libros", en Clara Janés. El fuego invisible, 26, su interés por los "Upanishads" data de cuando Carlos Barral los publicó.
} 
Muy revelador es el texto "El sueño es exterior" con que se cierra esta sección. El sueño va manifestando lo que ella llama la "sorpresa cuántica" donde percibe susurros de "astros sonámbulos", sombras donde se funden "unificados piedras plantas animales" e incluso "inteligencias angélicas / de verde hábito" ${ }^{2}$. La hablante se encuentra de lleno en la experiencia del enredo cuántico, habiendo así cumplido con el dictum de Heráclito de penetrar en las cosas y experimentar, como anunció Parménides, su totalidad. Los ángeles son presencias en los escritos de Janés, apuntando a un nivel mediador o tercero oculto entre extremos opuestos procedente de los escritos de Basarab Nicolescu y que, a su vez, se corresponde con el principio de complementariedad de Bohr. El hábito verde de los ángeles es el verde de la iluminación, como sucede en el sufismo. Y esos espíritus son los que constituyen la trama o enredo cósmico al lanzar al aire las "cintas" de sus hábitos "iluminando" el enredo con su verde lúcido. Y de ello emerge la poesía, "esa voz que penetra en la boca / y deja entre los labios el vocablo", marcando así el comienzo de la creación poética. Y, concomitantemente, se enuncia el "soy" de la hablante, la poeta observadora y el mundo observado en un enredo o trama de amor donde se configura la creatividad y la vida.

La sección "Relatividad" claramente alude a la teoría de Einstein e introduce la indeterminación en la lucidez adquirida en la sección anterior, ya que no se trata más de una realidad fija y estática sino configurada según sea la perspectiva. Por eso la ilustración muestra la conexión entre el manifestarse y el ocultarse aludiendo a la paradoja de la realidad en la relatividad pues su naturaleza depende del ángulo de mira. La iluminación no es total ya que la relatividad desbanca absolutismos e implica el engranaje de luz y sombra ${ }^{63}$.

El juego de revelación y ocultación en la relatividad se produce debido a la "curvatura del universo" o "abrazo curvo" que Bohr califica de enredos cuánticos ${ }^{64}$. En dicha curvatura el espacio y el tiempo son espaciotiempo y lo que hoy vemos o se manifiesta, como las estrellas, son restos o historia de lo que ocurrió hace millones de años. Por tanto, ¿cómo articular y entender la realidad cuando lo que vemos ya no es y lo que es no podemos vislumbrar? La misma paradoja se produce en la mente. Por eso, es acertado

62 Clara Janés, Orbes del sueño, 28.

63 Clara Janés, Orbes del sueño, 29.

64 Respecto al "abrazo curvo" como versión poética de la trama cósmica, y en torno a muchos de los temas aquí tratados, véase, Candelas Gala, Creative Cognition and the Cultural Panorama of Twentieth-Century Spain (New York: Palgrave Macmillan, 2016) y, en particular, el capítulo V sobre Janés, Chillida y María Zambrano titulado: "Creative Quietude. A Transdisciplinary Encounter: Clara Janés, Eduardo Chillida and María Zambrano”. 
recurrir a la simetría que Janés identifica con la belleza, entendiendo por tal el equilibrio entre los opuestos, o lo que Bohr clasificará como el principio de complementariedad. Si se logra la simetría será posible alcanzar una visión más completa y total que, al menos, calme "la inestabilidad del fragmento", aunque no por eso sea menos inestable ${ }^{65}$.

El enredo cuántico, el del abrazo curvo y la curvatura del universo implica la proximidad, por eso "en las manos / crece el saber", y así se confirma cuando dice que en la proximidad del tacto se muerde la manzana del saber de Newton. La inserción de la cita de Macrobio en medio de los poemas de esta sección sirve para reiterar lo que viene articulando en los poemas, es decir, reconocer la fusión de alma y cuerpo, del conocimiento corporal y del celestial frente a la clásica separación entre esos niveles. No hay división entre el intelecto y el cuerpo sino un abrazo curvo donde sus propiedades se complementan. Pero si el tacto no tiene lugar, entonces la inspiración se traduce en el canto falso de la sirena. Solo en la muerte es posible salir del enredo y llegar al origen donde, junto con la música reside el número -tanto par como impar-como punto en el tiempo donde los extremos se hallan perfectamente fusionados. La sección concluye con un poema dedicado a Sor Juana, una poeta que, como los filósofos ya citados, ilustra las nociones que la hablante viene desarrollando. Para la monja claridad y "materia oscura" se dan la mano, y el saber es no saber o saber de lo ignoto ${ }^{66}$.

En la sección "Universo infinito" la hablante se pregunta si todo el enredo cósmico solo se trata de "energía contenida en el vacío" 67 . La energía, como dijo anteriormente, es el único dios, y el vacío no es tal, sino que está pleno ${ }^{68}$. Menciona a Demócrito para afirmar la existencia de múltiples universos infinitos, que se reafirma en la cita a Giordano Bruno de que Dios es una esfera cuyo centro se halla en todas partes. Y como vimos en "Leyenda", vivimos en un universo que al expandirse carece de centro, desbancando la clásica noción de que la tierra es el centro. La existencia de múltiples e infinitos universos también se deshace del centro donde agarrarnos. Además, desconocemos su funcionamiento y ni podemos determinar su posición y movimiento, admitiendo la incertidumbre de Heisenberg. La pluralidad e infinitud de universos incluye la diferencia pues cada uno es distinto de los

65 Clara Janés, Orbes del sueño, 31.

66 Clara Janés, Orbes del sueño, 32, 33, 35, 36.

67 Clara Janés, Orbes del sueño, 37.

68 Wolfgang Pauli, Writings on Physics and Philosophy, 31, calificó a la energía como la verdadera sustancia, lo que se conserva, aunque la forma en que se manifiesta cambie. 
otros. Por eso concluye que tenemos "certidumbre de incertidumbre", y que lo único de que podemos estar ciertos es de que vivimos en la incertidumbre. Se va vislumbrando una realidad de "indisoluble indivisibilidad" o circunferencia con "infinitos centros" y con una "respiración global" donde el aquí y el allá comparten el mismo nido ${ }^{69}$.

Por eso se debe asumir, citando a Píndaro, que la existencia es leve, por lo que la hablante se pregunta si la existencia es sueño de una sombra o sombra de un sueño, logrando solo deducir que la consolidación de la multiplicidad de formas solo se producirá en el negro de la muerte. El deseo es llegar al límite y quedarse allí suspenso "en el desvanecerse / de los límites", en un anonadamiento del yo en la multiplicidad cósmica. La cita de Prigogine afirma que la vida "es el tiempo que se inscribe en la materia...", de ahí que haya que investigar la materia para mejor entender la naturaleza de la vida y del $\operatorname{cosmos}^{70}$.

"Zona de transparencia" anuncia un punto de luz en la búsqueda que se identifica con el cero donde el movimiento cesa al hallarse fuera de la gravedad. Para llegar a ese punto hay que seguir un proceso con tres direcciones identificadas en árabe como epígrafe del poema: "māyā" o la ilusión o estímulo para lograr el objetivo, "avidyā" o la ignorancia de no conocer el enigma y lo que implica y "adhyāsa" o la sobreimposición de distintas nociones, temas y preocupaciones al tratarse de una búsqueda no lineal. Por eso, evocando el poema de Alberti, "A galopar", el de Janés constata que no hay diferencia entre galopar o estar parado pues movimiento y quietud se dan unidos. Y así ocurre en el cero, cuya circularidad supone una "ronda incesante donde antes y después" se superponen ${ }^{71}$.

En su indagación la hablante se siente como otra constelación, "otro cuerpo errante / perdido en la oscuridad". La transparencia, entonces, es la de los números que se deslizan avanzando en la negrura y manteniendo el ritmo cósmico. Y para reafirmar lo dicho, cita a Aristóteles quien se refiere a la creencia de los pitagóricos en los números como elementos de todo lo existente. Aun así, carecemos de la llave para poder dilucidar su secreto, aunque nos movamos según el ritmo y movimiento numéricos ${ }^{72}$.

\footnotetext{
69 Clara Janés, Orbes del sueño, 39, 40, 41.

70 Clara Janés, Orbes del sueño, 42, 43.

71 Clara Janés, Orbes del sueño, 47.

72 Clara Janés, Orbes del sueño, 51, 52.
} 
La sección "Función de onda" alude a la onda en la ecuación matemática de Schrödinger que describe los cambios en el tiempo de un sistema físico donde cuentan en gran medida los efectos cuánticos, como el de la dualidad de onda y partícula. En la interpretación de Copenhague de la mecánica cuántica, la función de onda proporciona la descripción más completa de un sistema físico. De ahí que los poemas en esta sección insistan en la totalidad que está presente en todas las partes y que Janés elabora en un libro como Fractales. Se insiste también, como ya afirmó Schrödinger, en la importancia de los sentidos para el conocimiento, desmontando la primacía de la razón con su afán de analizar y dividir lo que estaba unido. En la totalidad cuántica sujeto y objeto, interioridad y exterioridad se funden, acabando con el distanciamiento de una observación desde fuera ${ }^{73}$.

Los números son los que urden la trama cósmica en la oscuridad, especialmente el número impar, y, además, nunca desaparecen. Cuando Galileo declaró que el sol se hallaba en el centro del universo ("y aquel año 1642 / que propició el salto / de un giro diverso"), el entendimiento del tiempo y del orden cósmico sufrió una gran perturbación — "quedó la flecha inquieta"-, además de que los cuerpos cayeran por la gravedad (Newton). El "incesante fluctuar" de la micropartícula reafirma la indeterminación del orden cósmico tanto en la luz como en la materia: la materia resulta ser una "trama viva" en la que el "cero-todo-potencia" ofrece un punto de respiro ${ }^{74}$.

La conciencia y subjetividad de la observadora / poeta tienen un papel definitivo en la creación. Bergson, en la cita incluida en esta sección, habla de la percepción donde la subjetividad entra de lleno, y su función de recordar lo que sabíamos, pero olvidamos. Y Janés concuerda pues cree que percibir es crear y es amar pues se crea el objeto percibido y al crearlo, se ama. Wheeler, en su cita, también señala el papel central de la subjetividad cuando dice que la conciencia y la información dominan el universo. Asocia lo irracional de esta situación cósmica con el sueño y su creatividad, y lo describe como "el sueño del cosmos / indeciso". Al entrar en la trama del universo y participar en la danza cósmica, los datos e información llegan y se intercambian con la memoria de lo que fue a la vez que se producen mutaciones o metamorfosis. Como la memoria es inestable, siempre se corre el peligro de la disipación. Aun así, esta vida es la única que tenemos y hay que vivirla en todos sus "remotos / espejos" o perspectivas de universos infinitos por inciertos e 
inestables que sean. La vida es inestable e incierta y hay que asumirla en sus infinitas manifestaciones ${ }^{75}$.

La sección titulada "El cero" elabora sobre ese número como un centro de potencia. La ilustración muestra una huella en la nieve que se vuelve signo en un intento de retener al signo mismo para impedir su fuga y la expansión del cosmos. Así, habla del negro de la noche o nigredo asociándolo con la lejanía y posiblemente con el redshift, ya que se refiere a estrellas apagadas. Percibe que en el negro las redes que constituyen la trama cósmica son quebradizas, como si al expandirse se fueran rompiendo. Solo en el presente se da una luz plena y por eso "presente" y "cero" se identifican como centros de potencia, aunque no por eso ofrezcan más certeza o libertad".

La cita de Michio Kaku confirma esta situación pues habla de la expansión del cosmos en oposición al cero ${ }^{77}$. Tras la expansión quedará un universo frío de agujeros negros, de partículas elementales a la deriva y de ausencia de bordes y límites debido a una fuga imparable donde "todo huye". Una posible solución es abandonarse a la lección de la naturaleza: "el compás acordado de los animales / y al serio orden de los árboles". Y así lo ejemplifica el poeta turco Dağlarca quien logró en su poesía escrita en la lengua turca hablar con estrella, piedras y montaña porque su palabra está en contacto directo con la naturaleza, frente a una palabra fósil y distanciada de la tierra. La expansión del cosmos, con la distancia de la palabra del entorno u objeto provocan la desarticulación de la trama de amor que es el universo. Teniendo en cuenta que la conexión de amor que Janés establece entre palabra y entorno, entre observador y observado es fundamental en la búsqueda de conocimiento, un distanciamiento afectaría la creatividad vital. Solo el cero es "infinito en potencia", "ida y regreso". Aun así, la hablante advierte que, de fijarse en el cero absoluto, la potencia se volvería inmovilidad, trayendo consigo el fin de los tiempos y la muerte del campo magnético ${ }^{78}$.

Cuando hacia 1900 se descubrió que el atomismo no se limita a la materia y que en la materia se da la indivisibilidad de procesos físicos, se llegó a la constatación que los procesos indivisibles están conectados lógicamente con

75 Clara Janés, Orbes del sueño, 64, 63, 65, 66.

76 Clara Janés, Orbes del sueño, 67, 69. Janés define los números oscuros como "cifra de lo incomunicable" que “a la vez ensanchan la propia visión” porque actúan "como espejos”, cit. en Jaime Siles, "Clara Janés: Vida secreta de y en las palabras", 35 .

77 Clara Janés, Orbes del sueño, 70.

78 Clara Janés, Orbes del sueño, 70, 71, 73, 72, 74. Ver también Clara Janés, "Las ecuaciones de la poesía: para una lectura de Orbes del sueño", 25. 
el problema de los números inexpresables (¿infinitos?), lo cual resultó en la creación de la mecánica cuántica en $1925^{79}$. Los "números oscuros" de que trata Janés en el libro de ese título, se conectan con el carácter secreto que tienen en la masonería y la numerología donde también poseen un carácter divino o místico. Desde los pitagóricos los números se asocian con la música (como se vio en el primer poema de Orbes), y Janés los asocia también con el latido del corazón, el tiempo, el sonido, la palabra y el pensamiento. Son "oscuros" porque no hay una explicación racional que abarque su infinitud. Sus mensajes o información son oscilantes pues revelan a la vez que ocultan. Pero la hablante sabe que transmiten mensajes, aunque no logre descifrarlos: "Los números oscuros son cifra de lo incomunicable y a la vez ensanchan la propia visión" ${ }^{80}$. Para Janés, los números son los elementos de todo lo existente y concuerda con los pitagóricos para quien "todo el cielo era armonía y número" $"$.

En cuanto al cero, "potencia sin contenido", es como un barco lanzado a la deriva, pero "cargado de amenazantes lanzas" pues su estabilidad no es permanente, y sugiere que quizá sea la rosa, el icono de la creatividad, donde anida el misterio de los números oscuros. Al no poder descifrar la infinitud de los números, la hablante apela al principio de incompletitud de Gödel, pues se trata de una "trama múltiple que dispersa el cálculo infinitesimal" Gödel ha mostrado, como indica Janés en Elpalabray el secreto, que no existe un sistema que permite demostrar la verdad o falsedad de todas las proposiciones matemáticas pues hay proposiciones indecidibles ya que, siendo infinitos, los números no pueden contarse ${ }^{83}$. El cero es el infinito en expansión.

El título "Supersimetría" para la sección ocho señala la posibilidad de una medición diferente de la regular pues, efectuada en fusión con el entorno, quizá permita esclarecer el enigma. Aunque se trata de una simetría hipotética, la supersimetría ofrece la posibilidad de entender la materia negra, las relaciones entre partículas elementales y el problema de la jerarquía. Por tanto, ofrece otra vía de conocimiento y medición que sirve como alternativa a la posible inmovilidad del cero ${ }^{84}$.

79 Aage Petersen, “The Philosophy of Niels Bohr", en Niels Bohr. A Centenary Volume, 303.

80 Clara Janés, Los números oscuros (Madrid: Siruela, 2006), 47-48.

81 Clara Janés, La palabra y el secreto, 101.

82 Clara Janés, Los números oscuros, 51, 55, 73.

83 Clara Janés, La palabra y el secreto, 104.

84 Clara Janés, Orbes del sueño, 75. La supersimetría es un modelo teórico e hipotético, como el de las supercuerdas. 
La ilustración que encabeza esta sección apunta a que la supersimetría permitiría una ubicuidad espacial del estar aquí y allí a la vez, o incluso de no estar, de presencia permanente e incluso de ausencia que no tiene consciencia de serlo. Por tanto, la supersimetría sería una manera de sobreponerse al distanciamiento debido a la expansión cósmica, aunque, como advierte Freeman Dyson, a quien Janés cita, la expansión cósmica podría llevar a la extinción. Y así les ocurrió a dinosaurios y a máquinas excesivamente pesadas y lentas, frente a los pájaros, mucho más pequeños y ligeros ${ }^{85}$. Ya en "Las ecuaciones" Janés, citando a Platón, dice que "el poder natural del ala es levantar lo pesado" hacia arriba donde "mora el linaje de los dioses" 86 . El consejo, entonces, es evitar la pesantez de animales enormes y seguir el ejemplo de los pájaros en tamaño y en velocidad para poder ascender a otros niveles de la realidad. Y así lo enseña Vedanta en la filosofía hindú: dejar de lado las jerarquías tanto de calidad como de tamaño, el menos y el más, pues no porque algo es enorme es más o mejor; lo pequeño puede ser más o igual. De no seguir esos ejemplos caeremos en la fuga de todo, en el deslizamiento "hacia una forma / que escapa / en remolinos". Y el final será la nada. Otro modo de escapar de ese deslizamiento es dejarse llevar por una serenidad en la naturaleza, como cuando el mar a medianoche es silencioso y sereno, aunque algo así no puede ser más que una idealización ${ }^{87}$.

La sección se cierra con citas de Henri Poincaré y de Edgard A. Poe sobre el conocimiento. Así como la supersimetría ofrece una vía de conocimiento con nuevas posibilidades, Poincaré dice que el pensamiento de la observadora y su consciencia proporcionan una lucidez rápida, como un relámpago de epifanía, en cuya brevedad misma se contiene todo. Y Poe afirma que no se trata de adquirir conocimiento sino de nunca dejar de conocer. Y a partir de ahí Janés extiende una invitación a seguir con la indagación pues implica una labor de creatividad, de amor y de vida.

Si se llega a un estado de inmovilidad y bienaventuranza, se trata de una entropía positiva que, como dice Prigogine, conduce a la muerte pues existir es movimiento, igual que el pensamiento y el conocimiento son movimientos. En la inmovilidad el "ahora" se deshace con la nada en acecho. Por eso la última sección, "Bifurcaciones sucesivas", alude a la teoría del caos de Prigogine donde las bifurcaciones dan pie a unas estructuras disipativas con las que se

85 Clara Janés, Orbes del sueño, 76.

86 Clara Janés, ““Las ecuaciones de la poesía: para una lectura de Orbes del sueño”, 11.

87 Clara Janés, Orbes del sueño, 77-80. 
establece un nuevo orden de reorganización. Las bifurcaciones se articulan como un estar aquí y ahora que es y "ya no es" 88 .

Y es la conciencia de la observadora / medidora en su indagación la que lleva a cabo la labor de creatividad, amor y vida en la escritura como análoga de las estructuras disipativas en la física del caos. Así lo indica la cita de Nicolescu que precede a la sección: la conciencia es la que constituye la discontinuidad de los sistemas caóticos necesarios para la vida, y a la inversa, la discontinuidad es la que constituye la conciencia. Pues, como la cita concluye: "La discontinuidad cuántica es uno de los signos de la conciencia cósmica"89.

En su libro de 2017 titulado Estructuras disipativas, Janés desarrolla a fondo el tema desde una perspectiva poética ${ }^{90} \mathrm{La}$ presencia de sistemas inestables en la física del no equilibrio hace insostenible el seguir manteniendo la noción del tiempo en términos de pasado y futuro. La física del caos describe los efectos del tiempo unidireccional, de la irreversibilidad, como ejemplifican los vórtices y las oscilaciones químicas, pero la irreversibilidad conduce también a la coherencia, pues sin la flecha del tiempo la vida en la tierra sería ininteligible. La vida se mantiene mediante una entropía negativa y, por tanto, se asocia con procesos irreversibles. Y el observador es quien en su función medidora introduce la irreversibilidad en el fluir del tiempo. La irreversibilidad conduce a estructuras disipativas o de no equilibrio que requieren la flecha del tiempo. Con su incorporación, las leyes de la dinámica no expresan certezas sino probabilidades ${ }^{91}$.

Por tanto, el no equilibrio lleva a una coherencia nueva, a una autoorganización que permite que la vida emerja. Y es así porque en el punto en que se da una desviación o clinamen en un sistema químico, llamado punto de bifurcación, se producen esos nuevos fenómenos llamados estructuras disipativas que son organizaciones espaciotemporales. Dichas estructuras suponen, como explica Prigogine, que el sistema no se desintegra en caos, sino que salta a otro orden u organización más diferenciada. Estas estructuras implican la presencia de espontaneidad, libertad y vida que en nada tienen que ver con la mecánica clásica de Newton ${ }^{92}$.

88 Clara Janés, Orbes del sueño, 81, 86, 88, 83, 87.

89 Clara Janés, Orbes del sueño, 85.

90 También discute esta sección de Orbes en "Las ecuaciones de la poesía: para una lectura de Orbes del sueño", 27.

91 Ilya Prigogine e Isabelle Stengers, The End of Certainty. Time, Chaos, and the New Law of Nature (New York: The Free Press, 1997), 3-5, 63, 126.

92 Ilya Prigogine e Isabelle Stengers, Order out of Chaos. Man's New Dialogue with Nature (Toronto: Bantam Books, 1984), 128, 66, 85 . 
Janés recurre a Nicolescu para corroborar el tema de las bifurcaciones sucesivas que ocurren en sistemas químicos de manera espontánea, ocasionando que la vida emerja. La cita de Santayana indica que la inteligencia es un injerto de la pasión o, en otras palabras, que es necesario mantener un diálogo complementario entre esos opuestos, de igual modo que las bifurcaciones introducen el azar, desafiando sistemas basados en rígidas abstracciones intelectuales. Y la de Sor Juana, "Yo, la peor de todas", encarna en la poeta mexicana la libertad de los sistemas químicos en la física del caos por haber desafiado los obstáculos que su cultura le impuso entregándose al saber como labor de amor, de creatividad y de vida. Y Sor Juana es, además, la peor de todas por atreverse a amar desde el "yo", afirmando su subjetividad y presencia en el contacto próximo con el mundo, por amar desde el tiempo, desde el aquí y el ahora, a pesar de su fugacidad, en reto a principios clásicos de eternidad y trascendencia, y desde la "leve sangre" de la fisicidad del cuerpo de la mujer. Como con Sta. Teresa, otra de las referencias centrales en Janés, las bifurcaciones sucesivas son la analogía física de un vivir al borde, experimentando el límite de lo imprevisible, de la complementariedad con la muerte: "el origen se pierde y el ahora / se deshace / en la acechante nada / que aún respiro", dice el poema por boca de Sor Juana ${ }^{93}$.

La complementariedad conlleva un rechazo del individualismo egocéntrico que se encierra en sí mismo sin contacto con el entorno, negando así el conocimiento y la vida. Hay que entender, sin embargo, que la indagación como labor de amor es un "viaje inmóvil", pues como dice Janés, "estar en un punto es estar en todos" ". Supone, además, un abrirse para acoger a un todo al que se refiere como "Aquello", objeto del amor, que quizá por eso lo escriba con mayúscula, como se haría con la palabra Dios. "Aquello" es el objeto de amor, la otredad de la creación, del mundo y de la vida. Al "Aquello" lanza la hablante sus "ecuaciones", como lo hicieron los físicos, que no son ni más ni menos que lazos de amor en los que quiere atraparlo. Así, la telaraña cósmica es una red urdida por el amor ${ }^{95}$.

Por eso recurre a la teoría hindú "satkaryavāda" que se opone a la causalidad ya que en la complementariedad del amor no hay jerarquías ni órdenes, sino mutua correlación. El deseo de la poeta radica en hallar el algoritmo que describa las contradicciones y explique el principio de la complementariedad

93 Clara Janés, Orbes del sueño, 85, 88.

94 Clara Janés, Orbes del sueño, 89; "Discurso de recepción del Premio Nacional de las Letras Españolas Teresa de Ávila”, 23.

95 Clara Janés, Orbes del sueño, 90. 
donde las jerarquías se disuelven en el más y el menos, el antes y el después, el aquí y el allá. Y esto es lo que ocurre en las bifurcaciones, ejemplos del "amor" del cosmos que produce ese salto para reorganizarse".

La sección se cierra con citas de Holan y del "Upanishad” para corroborar lo que se ha elaborado en los poemas. Para Holan el sentido del número se encuentra en su desaparición, ya que su supuesta exactitud es inabarcable debido a su infinitud e inalcanzable a la comprensión. Janés, por otro lado, y como ya se indicó en páginas anteriores, sigue a los pitagóricos en considerar el número como la esencia de todas las cosas. La paradoja entre ambas perspectivas, la de la desaparición, por un lado, y la de ser fundamento de todas las cosas, por otro, hace que el número se sustente en la complementariedad de esos contrarios. Una contradicción o paradoja semejante es la que expresa la cita del "Upanishad": "El ser es de quien huyen las palabras". En la complementariedad de poeta como observadora y el mundo como objeto de la observación, el lenguaje sirve para configurar el universo. Pero teniendo en cuenta el movimiento y la fuga de todo lo existente, las palabras apenas pueden captar las cosas y configurar su sentido ${ }^{97}$.

\section{Conclusiones}

La importancia que Bohr otorga al observador y a la conciencia en la física cuántica es fundamental para Janés y su búsqueda de conocimiento ${ }^{98}$. La hablante se pregunta por la conciencia, la memoria, el olvido, por su papel en configurar el conocimiento del cosmos y, semejante al científico, cuya subjetividad interviene al optar en el experimento de medición por un grupo de posibilidades dejando que otro colapse, la hablante ejerce sus propias opciones en cuanto al formato, ángulo y datos a incluir en su escritura. La observación, en el ejemplo macroscópico del felino de Shrödinger, hace que las cosas sucedan. Y así lo entiende Janés cuando escribe que la poeta “acepta

96 Clara Janés, Orbes del sueño, 91.

97 Clara Janés, Orbes del sueño, 93.

98 Eugene Wigner reconoció a Bohr como uno de los primeros en introducir la conciencia en la física cuántica, ver Juan Miguel Marín, "Mysticism in Quantum Mechanics: The Forgotten Controversy”, European Journal of Physics 30.4 (julio 2009): 807. 
este hecho y alcanza la serenidad que otorga el desconocimiento-conocimiento elegido" "99. Entiende así que el conocimiento nunca será absoluto ni estático.

En "The Philosophical Significance of the Idea of Complementarity" y en otros escritos, como en su artículo sobre Kepler, Pauli hace hincapié en la diferencia entre la proximidad del observador con el objeto en la física cuántica y el observador "distanciado" y pasivo en la física clásica. Esta situación le llevó a considerar la necesidad de extender el sistema de conocimiento para incluir cuestiones psicológicas relacionadas con la conciencia e, incluso, con el misticismo y las filosofías orientales. El efecto de la observación es tal, según Pauli, que da lugar a una transformación [Wandlung] semejante a la que se produce en la alquimia. Una transformación semejante también tiene lugar a nivel psicológico, pues el conocimiento que trae consigo la observación, en el sentido de hacer consciente algo que antes no lo era, produce un efecto evidente en el inconsciente. Por eso sugirió la posibilidad de llegar a un tipo de unidad psíquico-física, abriendo la ciencia a un nuevo tipo de conocimiento directamente conectado con el principio de complementariedad de Bohr, es decir, que dos elementos contrarios se complementen. Pauli concluye, entonces, que la interioridad y el mundo exterior se rigen por las mismas leyes cósmicas ${ }^{100}$.

Janés ha venido practicando la propuesta de Pauli desde los comienzos de su escritura. La incorporación de temas, teoremas, principios y ecuaciones científicas a la escritura poética refleja su convicción de que los acercamientos científicos y poéticos se complementan, y de que evidentemente se dan la correspondencia y congruencia (zur Deckung kommen) de que habla Pauli, y que ella misma señala ya en varios escritos entre imágenes interiores preexistentes que venimos almacenando desde el nacimiento y objetos del mundo exterior. Y sus citas y referencias a autores de muy diferentes culturas cumplen el deseo de Pauli de que el Occidente debiera responsabilizarse de fundir sus tradiciones con las del Este para así lograr una unidad de lo racional / crítico con lo irracional / místico ${ }^{101}$. En La palabra y el secreto Janés cita al biólogo Bose, quien ya en 1917 dijo que hay "sentimientos" en la célula lo cual, de ser así, implicaría que espíritu y materia son aspectos del mismo proceso,

99 Clara Janés, "Poetica de la rebelde ebriedad", 74.

100 Wolfgang Pauli, Writings on Physics and Philosophy, 22-24, 33-34.

101 Véase, por ejemplo, su "Discurso de recepción del Premio Nacional de las Letras Españolas Teresa de Ávila", 15. También Wolfgang Pauli, Writings on Physics and Philosophy, 126, 139. 
corroborando las teorías de Bohr y Pauli sobre las correspondencias entre el plano psíquico y el físico ${ }^{102}$.

Orbes del sueño describe la trayectoria de la hablante indagando en el enigma del universo. Al adentrarse de lleno en la totalidad de las cosas, experimenta en su proximidad mediante el sueño y la música y atiende a la presencia de variables ocultas que espera le permitan acceso a nuevas formas de conocimiento. De ahí percibe breves epifanías de iluminación sobre la trama cósmica y su constitución a la vez que constata la relatividad de ese conocimiento y la levedad de la existencia misma. Ya no hay un centro al que aferrarse sino una multiplicidad de opciones cósmicas, de universos infinitos donde quizá sean los números, y el cero, en particular, los que ofrezcan transparencia y alguna certeza a la que aferrarse. Pero los números se mantienen indescifrables y los límites entre sujeto y objeto solo conducen a una mayor paradoja porque todo queda enredado en la telaraña cósmica. La creciente expansión del universo amenaza con romper los lazos que mantienen la red cósmica y sus vibraciones, lo que conduce a experimentar con sistemas nuevos de medición, como la supersimetría. Es el cosmos mismo el que mediante las bifurcaciones se autoorganiza evitando su destrucción. La búsqueda de conocimiento llega así a reconocer el azar y la espontaneidad en el cosmos y su funcionamiento. A diferencia de Sor Juana, en cuyo honor Janés escribió Orbes, el resultado de un conocimiento parcial y limitado no es fuente de desengaño, como lo fue para la mexicana, sino algo positivo pues revela la continuidad del deseo de conocer donde reside el movimiento, la vida. Janés entiende que los sentidos son receptores abiertos y que a través de las sensaciones todo llega a la conciencia creándose un mundo interior que es reflejo del exterior. Reconoce, así, la necesidad de un conocimiento complementario entre los contrarios de razón e inconsciente, exterior e interior, cosmos y sujeto, conocimiento que confirma la complementariedad en el principio de Niels Bohr. 


\section{Bibliografía}

Barad, Karen. Meeting the universe halfway : quantum physics and the entanglement of matter and meaning. Durham y Londres: Duke University Press, 2007.

Bohm, David. "On Bohr's views concerning the quantum theory". En Niels Bohr. A Centenary Volume, editado por A. P. French A.P. y P. J. Kennedy, 153-159. Cambridge, Mass.: Harvard UP, 1985.

Bohm, David. "On the role of hidden variables in the fundamental structure of physics". Foundations of Physics 26.6 (Junio 1996): 719-786.

Bohm, David. Wholeness and the Implicate Order. London: Routledge y Keagan Paul, 1981.

Bohr, Niels. Atomic physics and buman knowledge. New York: John Wiley \& Sons, Inc. 1958.

Caro, Manuel J. y John W. Murphy, eds. The world of quantum culture. Wesport, Connecticut: Praeger, 2002.

Ciplijauskaité, Biruté. "Magia y misterio en Clara Janés". En Clara Janés. El fuego invisible, editado por Anne M. Pasero, 110-115. Ávila: Excelentísimo Ayuntamiento de Ávila, 2012.

Faszer-McMahon, Debra. "Explorando los signos del yo en Espacios traslúcidos". En Clara Janés. El fuego invisible, editado por Anne M. Pasero, 145151. Ávila: Excelentísimo Ayuntamiento de Ávila, 2012.

French A. P. y P. J. Kennedy, eds. Niels Bohr. A Centenary Volume. Cambridge, Mass.: Harvard University Press, 1985.

Gala, Candelas. Creative cognition and the cultural panorama of twentieth-century Spain. New York: Palgrave Macmillan, 2016.

Gamoneda, Antonio. "Presentación de Los números oscuros". En Clara Janés. El fuego Invisible, editado por Anne M. Pasero, 154-157. Ávila: Excelentísimo Ayuntamiento de Ávila, 2012.

Hayles, N. Katherine. The cosmic web. Scientific field models \& literary strategies in the 20 $0^{\text {th }}$ Century. Ithaca y Londres: Cornell University Press, 1984.

Heisenberg, Werner. "Reminiscences from 1926 and 1927”. En Niels Bohr. A Centenary Volume, editado por A. P. French y P. J. Kennedy, 163-171. Cambridge, Mass.: Harvard University Press, 1985. 
Janés, Clara. Estructuras disipativas. Barcelona: Tusquets, 2017.

Janés, Clara. La blanca forma de la fuga. Valladolid: Diputación de Valladolid, 2015.

Janés, Clara. Movimientos insomnes. Antología poética (1964-2014). Barcelona: Galaxia Gutenberg, 2015.

Janés, Clara. "Las ecuaciones de la poesía: para una lectura de Orbes del sueño." En Secretosy verdades en los textos de Clara Janés / Secrets and Truths in the Texts of Clara Janés, editado por Nadia Mékouar-Hertzberg, 3-28. Bern: Peter Lang, 2014.

Janés, Clara. Orbes del sueño. Madrid: Vaso roto, 2013.

Janés, Clara. Variables ocultas. Barcelona: Vaso roto, 2010.

Janés, Clara. "La vida, los libros". En Clara Janés. El fuego invisible, editado por Anne M. Pasero, 19-31. Ávila: Excelentísimo Ayuntamiento de Ávila, 2012.

Janés, Clara. "Poética de la rebelde ebriedad". En Clara Janés. El fuego invisible, editado por Anne M. Pasero, 69-74. Ávila: Excelentísimo Ayuntamiento de Ávila, 2012.

Janés, Clara. "Discurso de recepción del Premio Nacional de las Letras Españolas Teresa de Ávila". En Clara Janés. El fuego invisible, editado por Anne M. Pasero, 9-18. Ávila: Excelentísimo Ayuntamiento de Ávila, 2012.

Janés, Clara. Los números oscuros. Madrid: Siruela, 2006.

Janés, Clara. La palabra y el secreto. Madrid: Huerga y Fierro, 1999.

Janés, Clara. Jardín y laberinto. Madrid: Debate, 1990.

Janés, Clara. "Mi homenaje a Sor Juana". Texto enviado por la autora.

Jones, R. V. "Complementarity as a way of life". En Niels Bobr. A Centenary Volume, editado por A. P. French y P.J. Kennedy, 320-324. Cambridge, Mass.: Harvard University Press, 1985.

Kothari, D. S. "The complementarity principle and eastern philosophy". En Niels Bohr. A Centenary Volume, editado por A. P. French y P.J. Kennedy, 325-331. Cambridge, Mass.: Harvard University Press, 1985. 
MacKinnon, Edward. "Bohr on the foundations of quantum theory". En Niels Bohr. A Centenary Volume, editado por A. P. French y P.J. Kennedy, 101-120. Cambridge, Mass.: Harvard University Press, 1985.

Marín, Juan Miguel. "Mysticism in quantum mechanics: the forgotten controversy". European Journal of Physics 30.4 (julio 2009): 807-822.

Nicolescu, Basarab. Teoremas poéticos. Fotografías de Karl Blossfeldt. Selección y traducción de Clara Janés. Madrid: salto de página, 2013.

Nicolescu, Basarab. Manifesto of transdisciplinarity, tr. Karen-Claire Voss. Albany: State University of New York Press, 2002.

Ortega, Antonio. "El arco y la flecha: ciencia y poética en la escritura de Clara Janés". Épistemocritique 16 (octubre 30, 2017), http://epistemocritique.org/category/la-revue/volume-16-vers-une-epistemocritiquehispanique/

Pasero, Anne. "La autobiografía como expresión singular posmoderna: Jardín y laberinto." En Clara Janés. El fuego invisible, editado por Anne M. Pasero, 116-127. Ávila: Excelentísimo Ayuntamiento de Ávila, 2012.

Pauli, Wolfgang. Writings on Physics and Philosophy. Editado por Charles P. Enz y Karl von Meyenn. Traducido por Robert Schlapp. Berlin: SpringerVerlag, 1994.

Petersen, Aage. "The Philosophy of Niels Bohr". En Niels Bohr. A Centenary Volume, editado por A. P. French y P.J. Kennedy, 299-310. Cambridge, Mass.: Harvard University Press, 1985.

Prigogine, Ilya e Isabelle Stengers. The end of certainty. Time, chaos, and the new law of nature. New York: The Free Press, 1997.

Prigogine, Ilya e Isabelle Stengers. Order out of chaos. Man's new dialogue with nature. Toronto: Bantam Books, 1984.

Sarquís, Jorge y Jacob Buganza. "La teoría del conocimiento transdisciplinar a partir del Manifiesto de Basarab Nicolescu". Fundamentos en Humanidades 10.1 (19, 2009): 43-55.

Scaramuza Vidoni, Mariarosa. "Poesía y misterio en Clara Janés". En Clara Janés. El fuego Invisible, editado por Anne M. Pasero, 158-170. Ávila: Excelentísimo Ayuntamiento de Ávila, 2012. 
Schmelzer, Felix K. E. "'Vibra el vacío': interpretación de un poema de Clara Janés, a partir de la física cuántica". Wort und Zabl. Palabra y número, 219-230. Heidelberg: Universitätsverlag, 2015.

Siles, Jaime. "Clara Janés: Vida secreta de y en las palabras". En Movimientos insomnes. Antología poética (1964-2014), por Clara Janés, editado por Jaime Siles, 7-39. Barcelona: Galaxia-Gutenberg, 2014.

Villena, Luis Antonio de. "Esencias materiales (sobre el libro Fractales)". En Clara Janés. El fuego invisible, editado Anne M. Pasero, 130-131. Ávila: Excelentísimo Ayuntamiento de Ávila, 2012.

Wheeler, John A. "Physics in Copenhagen in 1934 and 1935". En Niels Bohr. A Centenary Volume, editado por A. P. French y P. J. Kennedy, 221-226. Cambridge, Mass.: Harvard UP, 1985.

Wilson, Jennifer. "Quantum aesthetics and art history". En The World of Quantum Culture, editado por Manuel J. Caro y John W. Murphy, 89-115. Wesport, Connecticut: Praeger, 2002. 